\title{
STUDI PERILAKU KELOMPOK TIANG UNTUK FONDASI TIANG BOR PADA KONDISI ELASTIK DAN TIDAK ELASTIK
}

\author{
Andrew $^{1}$, Giovanni Pranata ${ }^{2}$, dan Amelia Yuwono ${ }^{3}$ \\ ${ }^{1}$ Program Studi Sarjana Teknik Sipil, Universitas Tarumanagara, Jl. Letjen S. Parman No.1 Jakarta \\ Email: andrewsubahri@yahoo.com \\ ${ }^{2}$ Program Studi Sarjana Teknik Sipil, Universitas Tarumanagara, Jl. Letjen S. Parman No.1 Jakarta \\ Email: giovannip@ft.untar.ac.id \\ ${ }^{3}$ Program Studi Sarjana Teknik Sipil, Universitas Tarumanagara, Jl. Letjen S. Parman No.1 Jakarta \\ Email: amelia774@yahoo.com
}

\begin{abstract}
ABSTRAK
Fondasi merupakan suatu hal yang sangat berpengaruh terhadap suatu bangunan. Fondasi berfungsi untuk memikul beban aksial dan beban lateral. Kelompok tiang digunakan untuk meminimalisir kegagalan dari sebuah tiang. Karena adanya peningkatan percepatan gempa di daerah tertentu pada SNI 1726:2012, perlu dilakukan analisis terhadap kelompok tiang di daerah yang terkena peningkatan percepatan gempa. Dengan melakukan analisis pushover pada suatu kelompok tiang, tingkat kinerja suatu kelompok tiang dapat diketahui berdasarkan metode spektrum kapasitas yang diatur dalam ATC-40 dan Pushover Analysis of Underground Structutres.
\end{abstract}

Kata kunci: fondasi, kelompok tiang, tingkat kinerja, metode spektrum kapasitas, analisis pushover

\section{PENDAHULUAN}

\section{Latar Belakang}

Dalam bidang konstruksi, fondasi merupakan suatu hal yang sangat berpengaruh terhadap kekuatan suatu bangunan. Fondasi merupakan bagian yang paling bawah dari suatu bangunan dan langsung berhubungan dengan tanah. Fondasi berfungsi untuk memikul beban aksial dan beban lateral.

Salah satu jenis fondasi yang ada adalah fondasi tiang. Berdasarkan metode instalasinya, fondasi tiang dapat diklasifikasikan menjadi tiang pancang dan tiang bor. Meskipun pada tiang yang berdiameter besar atau untuk beban yang ringan sering digunakan fondasi tiang tunggal untuk memikul kolom atau beban struktur, namun pada umumnya beban kolom struktur atas dapat pula dipikul oleh suatu kelompok tiang. Penggunaan kelompok tiang biasa digunakan bila tiang tunggal tidak mempunyai kapasitas yang cukup untuk menahan beban kolom. Kelompok tiang juga berguna untuk meminimalisir kegagalan dari sebuah tiang dengan adanya tiang-tiang yang lain.

Diberlakukannya SNI 1726:2012 yang menggantikan SNI 1726:2002 sehingga ada daerah tertentu yang mengalami kenaikan percepatan gempa sehingga gaya gempa yang diterima fondasi meningkat. Oleh karena itu perlu dilakukan analisis terhadap suatu kelompok tiang dengan berbagai percepatan gempa pada kondisi elastik maupun tidak elastik, salah satunya adalah dengan analisis statik non linier atau analisis pushover.

Dari hasil analisis pushover terhadap suatu kelompok tiang tersebut dihasilkan kurva yang menghubungkan antara base shear dan roof displacement atau disebut kurva kapasitas. Dari kurva kapasitas tersebut dapat dilihat perilaku suatu kelompok tiang dari kondisi elastis sampai plastis hingga mengalami kegagalan. Dengan adanya kurva kapasitas yang diperoleh, kita dapat melihat tingkat kinerja suatu kelompok tiang berdasarkan metode spektrum kapasitas berdasarkan peraturan ATC-40 dan Pushover Analysis of Underground Structures.

\section{Batasan masalah}

Adapun batasan masalah yang akan dibahas adalah:

1. Data tanah diambil dari suatu proyek di daerah Pancoran, Jakarta Selatan.

2. Pemodelan kelompok tiang terhadap beban lateral dilakukan dengan bantuan program.

3. Pile yang digunakan adalah tiang bor bulat dengan dimensi $50 \mathrm{~cm}-90 \mathrm{~cm}$.

4. Konfigurasi kelompok tiang yang digunakan adalah 4 tiang, 5 tiang, dan 6 tiang.

5. Analisis hanya dilakukan terhadap tiang.

6. Gaya yang diterima tiang adalah gaya lateral.

7. Jenis tanah dimodifikasi mengikuti SNI 1726:2012. 


\section{Rumusan Masalah}

Rumusan masalah yang akan dibahas adalah:

1. Berapa besar gaya lateral maksimum yang dapat diterima kelompok tiang pada kondisi elastik dan tidak elastik?

2. Berapa besar displacement yang terjadi pada kelompok tiang yang diberikan gaya lateral maksimum pada kondisi elastik dan tidak elastik?

3. Bagaimana tingkat kinerja struktur pada tiang yang direncanakan dengan SNI $1726: 2012$ melalui analisis pushover menurut peraturan ATC-40 dan Pushover Analysis of Underground Structures?

\section{Tujuan Penelitian}

Tujuan dari penelitian ini antara lain:

1. Mengetahui besarnya gaya lateral maksimum yang dapat diterima kelompok tiang pada kondisi elastik dan tidak elastik.

2. Mengetahui besarnya displacement yang terjadi pada kelompok tiang yang diberikan gaya lateral maksimum pada kondisi elastik dan tidak elastik.

3. Mengetahui tingkat kinerja struktur pada tiang yang direncanakan dengan SNI $1726: 2012$ melalui analisis pushover menurut peraturan ATC-40 dan Pushover Analysis of Underground Structures.

\section{TINJAUAN PUSTAKA}

\section{Analisis Statik Non-Linier (Pushover Analysis)}

Analisis pushover adalah suatu cara analisis statik non-linier dimana pengaruh Gempa Rencana terhadap struktur bangunan gedung dianggap sebagai beban-beban static yang menangkap pada pusat massa masing-masing lantai, yang nilainya ditingkatkan secara berangsur-angsur sampai melampaui pembebanan yang menyebabkan terjadinya pelelehan (sendi plastis) pertama di dalam struktur bangunan gedung, kemudian dengan peningkatan beban lebih lanjut mengalami perubahan bentuk pasca-elastis yang besar sampai mencapai kondisi plastis.

Analisis dilakukan dengan memberikan suatu pola beban lateral statik pada struktur, yang kemudian secara bertahap ditingkatkan dengan faktor pengali sampai satu target perpindahan lateral dari suatu titik acuan tercapai. Pada proses pushover, struktur didorong sampai mengalami leleh disatu atau lebih lokasi di struktur tersebut. Kurva kapasitas akan memperlihatkan suatu kondisi linier sebelum mencapai kondisi leleh dan selanjutnya berperilaku non-linier. Kurva pushover dipengaruhi oleh pola distribusi gaya lateral yang digunakan sebagai beban dorong. Selain itu, analisis pushover juga dapat memperlihatkan secara visual perilaku struktur pada saat kondisi elastis, plastis dan sampai terjadinya keruntuhan pada elemen-elemen strukturnya.

Meskipun metode ini sangat sederhana, informasi yang dihasilkan sangat berguna karena mampu menggambarkan respons in-elastis bangunan ketika mengalami gempa. Analisis ini memang bukan cara yang terbaik untuk mendapatkan jawaban terhadap masalah-masalah analisis dan desain, tetapi cara ini relatif sederhana untuk mendapatkan respon non-linier suatu struktur.

\section{Kinerja Struktur}

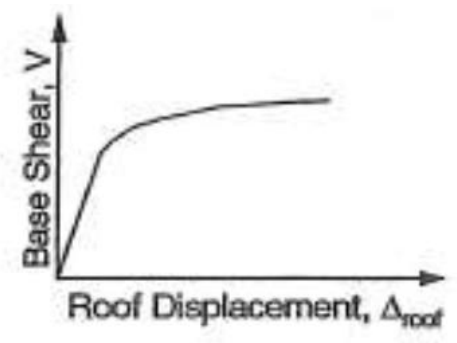

Gambar 1 Kurva Pushover

Kinerja struktur adalah tingkat/level performa suatu struktur dengan melihat tingkat kerusakannya saat terkena gempa rencana dengan periode ulang tertentu. Oleh karena itu, kinerja struktur erat kaitannya dengan biaya perbaikan terhadap bangunan tersebut. Semakin baik tingkat kinerja suatu struktur, maka semakin sedikit biaya perbaikan yang perlu dikeluarkan saat gempa rencana terjadi.

Dalam desain struktur berbasis kinerja, kinerja struktur didesain sesuai dengan fungsi bangunan tersebut dengan mempertimbangkan faktor ekonomis terhadap perbaikan bangunan saat terjadi gempa, tanpa mengesampingkan keselamatan pengguna bangunan itu sendiri. 


\section{Tingkat Kinerja Struktur Metode $\boldsymbol{A T C}$-40}

Dalam metode $A T C-40$, tingkat kinerja struktur ditentukan dengan menggunakan metode spektrum kapasitas (capacity-spectrum), yaitu dengan memplotkan demand respons spektrum dan kurva kapasitas dalam satu format antara spektral percepatan dan spektral perpindahan atau disebut sebagai format Acceleration-Displacement Response Spectra $(A D R S)$.

Kurva kapasitas (capacity-curve) diperoleh dari analisis pushover, yaitu analisis statik nonlinier dengan memberikan beban lateral statik tertentu pada struktur yang kemudian ditingkatkan secara bertahap hingga struktur mencapai suatu batas tertentu atau mengalami kegagalan struktur. Respons struktur terhadap beban lateral tersebut dicatat dan dibuat kurva hubungan antara gaya geser dasar, " $V$ " dan perpindahan pada atap, " $\Delta_{\text {atap }}$ ". Kurva tersebut-lah yang disebut sebagai kurva kapasitas.

Kurva kapasitas menggambarkan kekuatan struktur yang besarnya sangat tergantung dari kemampuan deformasi masing-masing elemen struktur. Untuk mengubah kurva kapasitas ke dalam format $A D R S$ atau menjadi spektrum kapasitas diperlukan pemahaman tentang hubungan faktor partisipasi modal, modal koefisien massa, dan perpindahan bangunan. Untuk mengubah kurva kapasitas ke dalam format ADRS digunakan persamaan

$$
\begin{aligned}
S_{a} & =\frac{V / W}{\alpha_{1}} \\
S_{d} & =\frac{\Delta_{\text {roof }}}{P F_{1} \phi_{\text {roof } .1}}
\end{aligned}
$$

dengan $\mathrm{V}=$ gaya geser dasar $(\mathrm{kN}), \mathrm{W}=$ berat tiang $(\mathrm{kN}), \alpha_{1}=$ modal koefisien massa pada mode pertama, $\Delta_{\text {roof }}=$ perpindahan atap $(\mathrm{m}), \mathrm{PF}=$ faktor partisipasi modal pada mode pertama

Demand spektrum diperoleh dengan mengubah respons spektrum yang biasanya dinyatakan dalam spektra percepatan " $S_{a}$ " dan periode " $T$ " menjadi format $A D R S\left(S_{a}, S_{d}\right)$ dengan menggunakan persamaan

$$
S_{d}=\frac{T^{2}}{4 \pi^{2}} S_{a} \cdot(g)
$$

dengan $\mathrm{Sa}=$ spektra percepatan $(\mathrm{m}), \mathrm{Sd}=$ spektra perpindahan $(\mathrm{g}), \mathrm{g}=$ percepatan gravitasi $\left(9.81 \mathrm{~m} / \mathrm{s}^{2}\right), \mathrm{T}=$ periode getar fundamental (detik)

Selanjutnya, grafik spektrum kapasitas dan spektrum demand digambarkan dalam satu grafik ADRS. Dalam grafik tersebut akan terjadi perpotongan antara spektrum kapasitas dan spektrum demand. Titik perpotongan tersebut disebut sebagai titik kinerja atau performance point. Redaman yang terjadi saat struktur terkena gerakan gempa pada keadaan inelastik dapat dilihat pada redaman viscous yang melekat pada struktur dan redaman histerestik.

Redaman histerestik (hysteretic damping) berhubungan dengan area di dalam loop kurva gaya dan perpindahan akibat gaya gempa. Redaman histerestik ini dapat mewakili redaman viscous ekuivalen. Dalam ATC-40 redaman viscous ekuivalen dirumuskan dengan persamaan

$$
\begin{aligned}
& \beta_{0} \quad=\frac{63.7(\text { ay.dpi-dy.api })}{\text { api.dpi }} \\
& \beta_{e q} \quad=\beta 0+5 \\
& S R_{A} \quad=\frac{3.21-0.68 \ln (\beta e q)}{2.12} \\
& S R_{V} \quad=\frac{2.31-0.41 \ln (\beta e q)}{1.65}
\end{aligned}
$$

dengan $\beta_{0}=$ redaman histerestis yang mewakili redaman viscous ekuivalen, $\beta_{e q}=$ redaman viscous ekuivalen struktur, 0.05 = redaman yang melekat pada struktur (redaman awal) 


\section{METODOLOGI PENELITIAN}

\section{Metode Pengumpulan Data}

Metode yang digunakan dalam pengumpulan data-data yang akan dipakai adalah dengan pengumpulan data dari proyek. Pada studi ini, data tanah akan dianalisis mengikuti SNI 1726:2012 yang berlokasi di daerah Pancoran, Jakarta Selatan. Data tanah yang dikumpulkan berupa boring log dan hasil tes laboratorium. Data tanah tersebut merupakan laporan penyelidikan tanah pada daerah tersebut.

\section{Metode Analisis Data}

Sebelum dilakukannya analisis data, dilakukan pembelajaran atau studi tentang teori-teori dasar yang berhubungan dengan topik pembahasan dalam penelitian yang akan dilakukan. Teori dasar yang digunakan sebagai acuan pembelajaran dapat dicari berdasarkan berbagai macam sumber, seperti jurnal, karya ilmiah, buku referensi yang akan berguna untuk mendapatkan rumus-rumus atau persamaan. Dalam melakukan analisis pushover mengacu pada ATC-40.

\section{ANALISIS DAN PEMBAHASAN}

\section{Hasil Analisis Kelompok Tiang 4 Tiang, 5 Tiang, dan 6 Tiang}

Setelah dilakukan analisis pushover, maka kita bisa mendapatkan beban maksimum untuk tiap kelompok tiang dan mendapatkan kurva kapasitas, kemudian diubah menjadi kurva spektrum kapasitas. Dari kurva tersebut kita bisa mendapat performance point dan pile drift ratio yang akan digunakan untuk menentukan tingkat kinerja kelompok tiang.

Tabel 1. Hasil Analisis 4 Tiang

\begin{tabular}{|c|c|c|c|c|c|c|c|}
\hline $\begin{array}{c}\text { Diameter } \\
\text { Tiang }(\mathrm{mm})\end{array}$ & Tipe Tiang & Beban (kN) & $\begin{array}{l}\text { Fixed End } \\
\text { Length }(\mathrm{m})\end{array}$ & $\begin{array}{c}\text { Performance } \\
\text { Point }\end{array}$ & $\begin{array}{l}\text { Pile Drift } \\
\quad \text { Ratio }\end{array}$ & Kategori & Kesimpulan \\
\hline \multirow{4}{*}{500} & \multirow[b]{2}{*}{ Elastik } & \multirow[b]{2}{*}{1800} & \multirow[b]{2}{*}{11.1} & \multirow[b]{2}{*}{0.1175} & \multirow[b]{2}{*}{0.0106} & $0.01-0.02$ & $\begin{array}{c}\text { Damage } \\
\text { Control }\end{array}$ \\
\hline & & & & & & $<1.5 \%$ & $\begin{array}{c}\text { Irreparable, } \\
\text { Life safe- } \\
\text { damage state }\end{array}$ \\
\hline & \multirow[b]{2}{*}{$\begin{array}{c}\text { Non Elastik } \\
\text { Tulangan } 1 \%\end{array}$} & \multirow[b]{2}{*}{450} & \multirow[b]{2}{*}{3.9} & \multirow[b]{2}{*}{0.0956} & \multirow[b]{2}{*}{0.0245} & $0.33 \mathrm{Vi} / \mathrm{Pi}$ & $\begin{array}{c}\text { Structural } \\
\text { Stability }\end{array}$ \\
\hline & & & & & & $<2.5 \%$ & $\begin{array}{c}\text { Severe, Near } \\
\text { collapse, } \\
\text { limited safety, } \\
\text { hazard } \\
\text { reduced } \\
\end{array}$ \\
\hline \multirow{4}{*}{600} & \multirow[b]{2}{*}{ Elastik } & \multirow[b]{2}{*}{2310} & \multirow[b]{2}{*}{17.1} & \multirow[b]{2}{*}{0.16} & \multirow[b]{2}{*}{0.0093} & 0.01 & $\begin{array}{l}\text { Immediate } \\
\text { Occupancy }\end{array}$ \\
\hline & & & & & & $<1.5 \%$ & $\begin{array}{l}\text { Irreparable, } \\
\text { Life safe- } \\
\text { damage state }\end{array}$ \\
\hline & \multirow{2}{*}{$\begin{array}{l}\text { Non Elastik } \\
\text { Tulangan } 1 \%\end{array}$} & \multirow[b]{2}{*}{550} & \multirow[b]{2}{*}{4.5} & \multirow[b]{2}{*}{0.0669} & \multirow[b]{2}{*}{0.0149} & $0.01-0.02$ & $\begin{array}{c}\text { Damage } \\
\text { Control } \\
\end{array}$ \\
\hline & & & & & & $<1.5 \%$ & $\begin{array}{c}\text { Irreparable, } \\
\text { Life safe- } \\
\text { damage state }\end{array}$ \\
\hline \multirow{4}{*}{700} & \multirow[b]{2}{*}{ Elastik } & \multirow[b]{2}{*}{4400} & \multirow[b]{2}{*}{18} & \multirow[b]{2}{*}{0.16} & \multirow[b]{2}{*}{0.0089} & 0.01 & $\begin{array}{l}\text { Immediate } \\
\text { Occupancy }\end{array}$ \\
\hline & & & & & & $<1.5 \%$ & $\begin{array}{c}\text { Irreparable, } \\
\text { Life safe- } \\
\text { damage state }\end{array}$ \\
\hline & \multirow[b]{2}{*}{$\begin{array}{l}\text { Non Elastik } \\
\text { Tulangan } 1 \%\end{array}$} & \multirow[b]{2}{*}{860} & \multirow[b]{2}{*}{5.4} & \multirow[b]{2}{*}{0.0933} & \multirow[b]{2}{*}{0.0173} & $0.01-0.02$ & $\begin{array}{l}\text { Damage } \\
\text { Control }\end{array}$ \\
\hline & & & & & & $<1.5 \%$ & $\begin{array}{c}\text { Irreparable, } \\
\text { Life safe- } \\
\text { damage state }\end{array}$ \\
\hline
\end{tabular}


Tabel 1. Hasil Analisis 4 Tiang (Lanjutan)

\begin{tabular}{|c|c|c|c|c|c|c|c|}
\hline \multirow{4}{*}{800} & \multirow[b]{2}{*}{ Elastik } & \multirow[b]{2}{*}{5300} & \multirow[b]{2}{*}{21.3} & \multirow[b]{2}{*}{0.19} & \multirow[b]{2}{*}{0.0089} & 0.01 & \multirow{2}{*}{$\begin{array}{c}\text { Immediate } \\
\text { Occupancy }\end{array}$} \\
\hline & & & & & & $<1.5 \%$ & \\
\hline & \multirow{2}{*}{$\begin{array}{l}\text { Non Elastik } \\
\text { Tulangan } 1 \%\end{array}$} & \multirow[t]{2}{*}{1140} & \multirow[t]{2}{*}{6.3} & \multirow[t]{2}{*}{0.189} & \multirow[t]{2}{*}{0.03} & $0.33 \mathrm{Vi} / \mathrm{Pi}$ & $\begin{array}{c}\text { Structural } \\
\text { Stability }\end{array}$ \\
\hline & & & & & & $>2.5 \%$ & Collapse \\
\hline \multirow{4}{*}{900} & \multirow[b]{2}{*}{ Elastik } & \multirow[b]{2}{*}{9900} & \multirow[b]{2}{*}{24.6} & \multirow[b]{2}{*}{0.19} & \multirow[b]{2}{*}{0.0077} & 0.01 & $\begin{array}{l}\text { Immediate } \\
\text { Occupancy }\end{array}$ \\
\hline & & & & & & $<1.5 \%$ & $\begin{array}{c}\text { Irreparable, } \\
\text { Life safe- } \\
\text { damage state }\end{array}$ \\
\hline & \multirow[b]{2}{*}{$\begin{array}{l}\text { Non Elastik } \\
\text { Tulangan } 1 \%\end{array}$} & \multirow[b]{2}{*}{1500} & \multirow[b]{2}{*}{7.3} & \multirow[b]{2}{*}{0.1759} & \multirow[b]{2}{*}{0.0244} & $0.33 \mathrm{Vi} / \mathrm{Pi}$ & $\begin{array}{l}\text { Structural } \\
\text { Stability }\end{array}$ \\
\hline & & & & & & $<2.5 \%$ & $\begin{array}{c}\text { Near } \\
\text { collapse, } \\
\text { limited safety, } \\
\text { hazard } \\
\text { reduced }\end{array}$ \\
\hline
\end{tabular}

Tabel 2. Hasil Analisis 5 Tiang

\begin{tabular}{|c|c|c|c|c|c|c|c|}
\hline $\begin{array}{c}\text { Diameter } \\
\text { Tiang (mm) }\end{array}$ & Tipe Tiang & Beban (kN) & $\begin{array}{l}\text { Fixed End } \\
\text { Length }(\mathrm{m})\end{array}$ & $\begin{array}{c}\text { Performance } \\
\text { Point }\end{array}$ & Pile Drift Ratio & Kategori & Kesimpulan \\
\hline \multirow{4}{*}{500} & \multirow[b]{2}{*}{ Elastik } & \multirow[b]{2}{*}{2390} & \multirow[b]{2}{*}{10.8} & \multirow[b]{2}{*}{0.1076} & \multirow[b]{2}{*}{0.01} & 0.01 & $\begin{array}{l}\text { Immediate } \\
\text { Occupancy }\end{array}$ \\
\hline & & & & & & $<1.5 \%$ & $\begin{array}{c}\text { Irreparable, } \\
\text { Life safe- } \\
\text { damage state }\end{array}$ \\
\hline & \multirow[b]{2}{*}{$\begin{array}{c}\text { Non Elastik } \\
\text { Tulangan } 1 \%\end{array}$} & \multirow[b]{2}{*}{550} & \multirow[b]{2}{*}{3.9} & \multirow[b]{2}{*}{0.0799} & \multirow[b]{2}{*}{0.0205} & $0.33 \mathrm{Vi} / \mathrm{Pi}$ & $\begin{array}{l}\text { Structural } \\
\text { Stability }\end{array}$ \\
\hline & & & & & & $<2.5 \%$ & $\begin{array}{c}\text { Severe, Near } \\
\text { collapse, } \\
\text { limited safety, } \\
\text { hazard } \\
\text { reduced } \\
\end{array}$ \\
\hline \multirow{4}{*}{600} & \multirow[b]{2}{*}{ Elastik } & \multirow[b]{2}{*}{2760} & \multirow[b]{2}{*}{16.2} & \multirow[b]{2}{*}{0.16} & \multirow[b]{2}{*}{0.0098} & 0.01 & $\begin{array}{l}\text { Immediate } \\
\text { Occupancy }\end{array}$ \\
\hline & & & & & & $<1.5 \%$ & $\begin{array}{c}\text { Irreparable, } \\
\text { Life safe- } \\
\text { damage state }\end{array}$ \\
\hline & \multirow[b]{2}{*}{$\begin{array}{c}\text { Non Elastik } \\
\text { Tulangan } 1 \%\end{array}$} & \multirow[b]{2}{*}{570} & \multirow[b]{2}{*}{4.2} & \multirow[b]{2}{*}{0.0438} & \multirow[b]{2}{*}{0.0104} & $0.01-0.02$ & $\begin{array}{c}\text { Damage } \\
\text { Control }\end{array}$ \\
\hline & & & & & & $<1.5 \%$ & $\begin{array}{c}\text { Irreparable, } \\
\text { Life safe- } \\
\text { damage state }\end{array}$ \\
\hline \multirow{4}{*}{700} & \multirow[b]{2}{*}{ Elastik } & \multirow[b]{2}{*}{6460} & \multirow[b]{2}{*}{18.3} & \multirow[b]{2}{*}{0.16} & \multirow[b]{2}{*}{0.0087} & 0.01 & $\begin{array}{l}\text { Immediate } \\
\text { Occupancy }\end{array}$ \\
\hline & & & & & & $<1.5 \%$ & $\begin{array}{l}\text { Irreparable, } \\
\text { Life safe- } \\
\text { damage state }\end{array}$ \\
\hline & \multirow[b]{2}{*}{$\begin{array}{c}\text { Non Elastik } \\
\text { Tulangan } 1 \%\end{array}$} & \multirow[b]{2}{*}{590} & \multirow[b]{2}{*}{4.5} & \multirow[b]{2}{*}{0.0283} & \multirow[b]{2}{*}{0.0063} & 0.01 & $\begin{array}{l}\text { Immediate } \\
\text { Occupancy }\end{array}$ \\
\hline & & & & & & $<1.5 \%$ & $\begin{array}{l}\text { Irreparable, } \\
\text { Life safe- } \\
\text { damage state }\end{array}$ \\
\hline
\end{tabular}


Studi Perilaku Kelompok Tiang untuk Fondasi Tiang Bor

Andrew, et al pada Kondis Elastik dan Tidak Elastik

Tabel 2. Hasil Analisis 5 Tiang (Lanjutan)

\begin{tabular}{|c|c|c|c|c|c|c|c|}
\hline \multirow{4}{*}{800} & \multirow[b]{2}{*}{ Elastik } & \multirow[b]{2}{*}{8000} & \multirow[b]{2}{*}{21.9} & \multirow[b]{2}{*}{0.1983} & \multirow[b]{2}{*}{0.009} & 0.01 & \multirow{2}{*}{$\begin{array}{c}\text { Immediate } \\
\text { Occupancy } \\
\text { Irreparable, } \\
\text { Life safe- } \\
\text { damage state }\end{array}$} \\
\hline & & & & & & $<1.5 \%$ & \\
\hline & & & & & & 0.01 & $\begin{array}{l}\text { Immediate } \\
\text { Occupancy }\end{array}$ \\
\hline & $\begin{array}{l}\text { Non Elastik } \\
\text { Tulangan } 1 \%\end{array}$ & 680 & 5.4 & 0.0275 & 0.0051 & $<1.5 \%$ & $\begin{array}{l}\text { Irreparable, } \\
\text { Life safe- } \\
\text { damage state }\end{array}$ \\
\hline \multirow{4}{*}{900} & \multirow[b]{2}{*}{ Elastik } & \multirow[b]{2}{*}{10000} & \multirow[b]{2}{*}{23.7} & \multirow[b]{2}{*}{0.17} & \multirow[b]{2}{*}{0.0072} & 0.01 & $\begin{array}{l}\text { Immediate } \\
\text { Occupancy }\end{array}$ \\
\hline & & & & & & $<1.5 \%$ & $\begin{array}{c}\text { Irreparable, } \\
\text { Life safe- } \\
\text { damage state }\end{array}$ \\
\hline & \multirow{2}{*}{$\begin{array}{l}\text { Non Elastik } \\
\text { Tulangan } 1 \%\end{array}$} & \multirow[b]{2}{*}{1160} & \multirow[b]{2}{*}{6} & \multirow[b]{2}{*}{0.0478} & \multirow[b]{2}{*}{0.0079} & 0.01 & $\begin{array}{l}\text { Immediate } \\
\text { Occupancy }\end{array}$ \\
\hline & & & & & & $<1.5 \%$ & $\begin{array}{c}\text { Irreparable, } \\
\text { Life safe- } \\
\text { damage state }\end{array}$ \\
\hline
\end{tabular}

Tabel 3. Hasil Analisis 6 Tiang

\begin{tabular}{|c|c|c|c|c|c|c|c|}
\hline $\begin{array}{c}\text { Diameter } \\
\text { Tiang }(\mathrm{mm})\end{array}$ & Tipe Tiang & Beban $(\mathrm{kN})$ & $\begin{array}{l}\text { Fixed End } \\
\text { Length }(\mathrm{m})\end{array}$ & $\begin{array}{c}\text { Performance } \\
\text { Point }\end{array}$ & $\begin{array}{l}\text { Pile Drift } \\
\quad \text { Ratio }\end{array}$ & Kategori & Kesimpulan \\
\hline \multirow{4}{*}{500} & \multirow[b]{2}{*}{ Elastik } & \multirow[b]{2}{*}{2660} & \multirow[b]{2}{*}{10.8} & \multirow[b]{2}{*}{0.1184} & \multirow[b]{2}{*}{0.011} & $0.01-0.02$ & $\begin{array}{c}\text { Damage } \\
\text { Control }\end{array}$ \\
\hline & & & & & & $<1.5 \%$ & $\begin{array}{c}\text { Irreparable, } \\
\text { Life safe- } \\
\text { damage state }\end{array}$ \\
\hline & \multirow[b]{2}{*}{$\begin{array}{l}\text { Non Elastik } \\
\text { Tulangan } 1 \%\end{array}$} & \multirow[b]{2}{*}{620} & \multirow[b]{2}{*}{3.9} & \multirow[b]{2}{*}{0.0657} & \multirow[b]{2}{*}{0.0168} & $0.01-0.02$ & $\begin{array}{l}\text { Damage } \\
\text { Control }\end{array}$ \\
\hline & & & & & & $<2.5 \%$ & $\begin{array}{c}\text { Severe, Near } \\
\text { collapse, limited } \\
\text { safety, hazard } \\
\text { reduced }\end{array}$ \\
\hline \multirow{4}{*}{600} & \multirow[b]{2}{*}{ Elastik } & \multirow[b]{2}{*}{2990} & \multirow[b]{2}{*}{12.9} & \multirow[b]{2}{*}{0.1313} & \multirow[b]{2}{*}{0.0102} & $0.01-0.02$ & $\begin{array}{c}\text { Damage } \\
\text { Control }\end{array}$ \\
\hline & & & & & & $<1.5 \%$ & $\begin{array}{l}\text { Irreparable, } \\
\text { Life safe- } \\
\text { damage state }\end{array}$ \\
\hline & \multirow[b]{2}{*}{$\begin{array}{l}\text { Non Elastik } \\
\text { Tulangan } 1 \%\end{array}$} & \multirow[b]{2}{*}{820} & \multirow[b]{2}{*}{4.5} & \multirow[b]{2}{*}{0.0679} & \multirow[b]{2}{*}{0.0151} & $0.01-0.02$ & $\begin{array}{l}\text { Damage } \\
\text { Control }\end{array}$ \\
\hline & & & & & & $<2.5 \%$ & $\begin{array}{c}\text { Severe, Near } \\
\text { collapse, limited } \\
\text { safety, hazard } \\
\text { reduced }\end{array}$ \\
\hline \multirow{4}{*}{700} & \multirow[b]{2}{*}{ Elastik } & \multirow[b]{2}{*}{4990} & \multirow[b]{2}{*}{17.7} & \multirow[b]{2}{*}{0.18} & \multirow[b]{2}{*}{0.0101} & $0.01-0.02$ & $\begin{array}{l}\text { Damage } \\
\text { Control }\end{array}$ \\
\hline & & & & & & $<1.5 \%$ & $\begin{array}{c}\text { Irreparable, } \\
\text { Life safe- } \\
\text { damage state }\end{array}$ \\
\hline & \multirow{2}{*}{$\begin{array}{l}\text { Non Elastik } \\
\text { Tulangan } 1 \%\end{array}$} & \multirow[b]{2}{*}{1170} & \multirow[b]{2}{*}{5.1} & \multirow[b]{2}{*}{0.0732} & \multirow[b]{2}{*}{0.0144} & $0.01-0.02$ & $\begin{array}{l}\text { Damage } \\
\text { Control }\end{array}$ \\
\hline & & & & & & $<1.5 \%$ & $\begin{array}{c}\text { Irreparable, } \\
\text { Life safe- } \\
\text { damage state }\end{array}$ \\
\hline
\end{tabular}


Tabel 3. Hasil Analisis 6 Tiang (Lanjutan)

\begin{tabular}{|c|c|c|c|c|c|c|c|}
\hline \multirow{4}{*}{800} & \multirow[b]{2}{*}{ Elastik } & \multirow[b]{2}{*}{5950} & \multirow[b]{2}{*}{18} & \multirow[b]{2}{*}{0.1983} & \multirow[b]{2}{*}{0.011} & $0.01-0.02$ & \multirow{2}{*}{$\begin{array}{c}\text { Damage } \\
\text { Control } \\
\text { Irreparable, } \\
\text { Life safe- } \\
\text { damage state }\end{array}$} \\
\hline & & & & & & $<1.5 \%$ & \\
\hline & \multirow{2}{*}{$\begin{array}{c}\text { Non Elastik } \\
\text { Tulangan } 1 \%\end{array}$} & \multirow[b]{2}{*}{1670} & \multirow[b]{2}{*}{10.5} & \multirow[b]{2}{*}{0.1405} & \multirow[b]{2}{*}{0.0134} & $0.01-0.02$ & $\begin{array}{c}\text { Damage } \\
\text { Control }\end{array}$ \\
\hline & & & & & & $<1.5 \%$ & $\begin{array}{c}\text { Irreparable, } \\
\text { Life safe- } \\
\text { damage state }\end{array}$ \\
\hline \multirow{4}{*}{900} & \multirow[b]{2}{*}{ Elastik } & \multirow[b]{2}{*}{10600} & \multirow[b]{2}{*}{23.7} & \multirow[b]{2}{*}{0.19} & \multirow[b]{2}{*}{0.008} & 0.01 & $\begin{array}{l}\text { Immediate } \\
\text { Occupancy }\end{array}$ \\
\hline & & & & & & $<1.5 \%$ & $\begin{array}{c}\text { Irreparable, } \\
\text { Life safe- } \\
\text { damage state }\end{array}$ \\
\hline & \multirow[b]{2}{*}{$\begin{array}{l}\text { Non Elastik } \\
\text { Tulangan } 1 \%\end{array}$} & \multirow[b]{2}{*}{2220} & \multirow[b]{2}{*}{13.2} & \multirow[b]{2}{*}{0.1731} & \multirow[b]{2}{*}{0.0131} & $0.01-0.02$ & $\begin{array}{c}\text { Damage } \\
\text { Control }\end{array}$ \\
\hline & & & & & & $<1.5 \%$ & $\begin{array}{l}\text { Irreparable, } \\
\text { Life safe- } \\
\text { damage state }\end{array}$ \\
\hline
\end{tabular}

Dari Tabel 1, Tabel 2, dan Tabel 3 didapat bahwa untuk kondisi elastik maupun non elastik, semakin besar diameter tiang, maka beban lateral maksimum yang dapat diterima tiang semakin besar. Dan semakin besar diameter tiang maka tingkat kinerja tiang semakin baik. Dan didapat bahwa kelompok tiang pada kondisi elastik lebih baik daripada kondisi non elastik.

\section{KESIMPULAN}

Berdasarkan analisis yang dilakukan, didapatkan beberapa kesimpulan sebagai berikut:

1. Berdasarkan hasil studi, semakin besar diameter tiang dan jumlah tiang dalam suatu kelompok tiang, maka semakin besar beban lateral maksimum yang dapat diterima tiap tiang pada suatu kelompok tiang untuk kondisi elastik dan tidak elastik.

2. Kelompok tiang pada kondisi elastik mampu menahan beban maksimum yang jauh lebih besar dari pada kelompok tiang pada kondisi tidak elastik

3. Berdasarkan nilai performance point yang didapat untuk 4 kelompok tiang, 5 kelompok tiang, dan 6 kelompok tiang untuk kondisi elastik dan tidak elastik, semakin besar diameter tiang dalam suatu kelompok tiang, maka nilai Pile drift ratio yang didapat cenderung semakin kecil yang berarti tingkat kinerja suatu tiang semakin baik.

\section{DAFTAR PUSTAKA}

ATC-40. 1996. Seismic Evaluation and Retrofit of Concrete Buildings Volume 1. California: Applied Technology Council.

Badan Standardisasi Nasional. 2012. Tata Cara Perencanaan Ketahanan Gempa untuk Struktur Bangunan Gedung dan Non Gedung (SNI 1726:2012). Jakarta: Badan Standardisasi Nasional.

Rahardjo, P.P. (2005). Manual Pondasi Tiang Edisi 3. Bandung: Publikasi GEC, Universitas Katolik Parahyangan. 
Studi Perilaku Kelompok Tiang untuk Fondasi Tiang Bor

Andrew, et al pada Kondis Elastik dan Tidak Elastik 